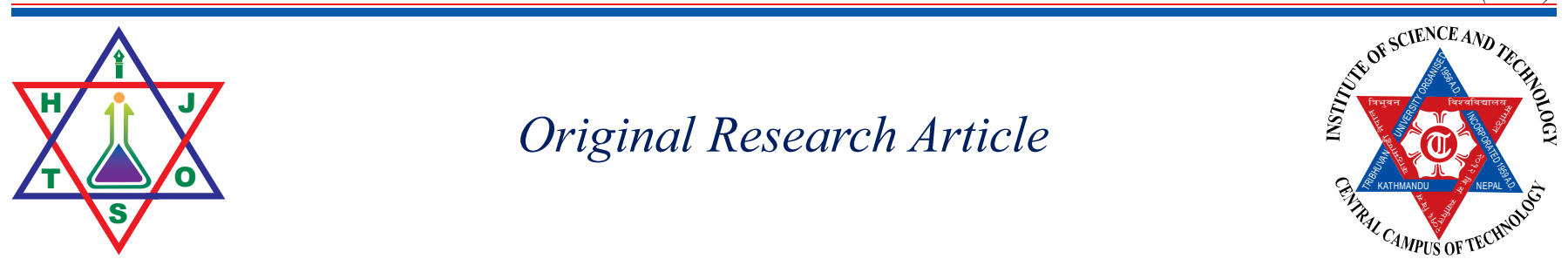

\title{
Effect of Processing Variables on Anthocyanin and Total Polyphenol Extraction from Water Caltrop (Trapa bispinosa) Hull \\ Babita Adhikari ${ }^{l^{*}}$ and Ojeswi Krishna Shrestha
}

${ }^{1}$ Central Campus of Technology, Tribhuvan University, Dharan, Nepal

*Corresponding Author: Babita Adhikari, Central Campus of Technology, Tribhuvan University, Dharan, Nepal,E-mail: babita_adhikari2016@yahoo.com

\begin{abstract}
:
Anthocyanins are water soluble pigments responsible for the brilliant orange red through deep purple colors in flower and fruits. The effects of different extraction variables $(\mathrm{pH}$, particle size, temperature and time, extraction method) on anthocynin, total polyphenol content and antioxidant of the extracts were studied. The anthocyanin content of fresh and dried $\left(55^{\circ} \mathrm{C}\right.$ for $2 \mathrm{~h}$ ) water caltrop hull were 68.68 and $44.38 \mu \mathrm{g} / 100 \mathrm{~g}$ d.b. respectively. Temperature, particle size and $\mathrm{pH}$ played a significant role $(\mathrm{p}<0.05)$ in aqueous extraction of anthonycinin. The optimum aqueous extraction condition were $\mathrm{pH}$ of 4.49 , particle size of $300 \mu \mathrm{m}$, temperature of $67.2^{\circ} \mathrm{C}$ and time of 25.38 min which gave $70.3 \%$ anthocynin extraction. There was a significant effect of extraction method (acidified ethanol, acidified ethanol and $\mathrm{pH}$ differential methods) and particles size on anthocynin extraction $(\mathrm{p}<0.05)$. The total polyphenol content in the aqueous extracts from water caltrop hull powder of 300,690 and $1080 \mu \mathrm{m}$ were in the range of 55.02-60.31 mg GAE $/ \mathrm{g} \mathrm{dm}$. The extraction of total polyphenol from $300 \mu \mathrm{m}$ was significantly different from 690 and $1080 \mu \mathrm{m}$ particle sizes, while there was no significant difference between from 690 and $1080 \mu \mathrm{m}$ respectively $(p>0.05)$. The particle size had a significant effect $(p<0.05)$ on the antioxidant activity of the extract and the values ranged from $173.36 \mu \mathrm{g} / \mathrm{mL}$ to $193.69 \mu \mathrm{g} / \mathrm{mL}$.
\end{abstract}

Key words: Water caltrop, anthocyanin, polyphenol, antioxidant activity, sorption isotherm

\section{Introduction}

Polyphenols are secondary metabolites of plants and are generally involved in defense against ultraviolet radiation or aggression by pathogens (Pandey and Rizvi, 2009). Plant polyphenols have been implicated for disease resistances (Bravo, 1998). In foods, polyphenoles may contribute to the bitterness, astringency, color, flavor, odor and oxidative stability and their stable radical intermediates prevent the oxidation of various food ingredients, particularly, fatty acids and oil (Maillard et al, 1996). The consumption of diets rich in plant polyphenols offered some protection against development of cancers, cardiovascular diseases, diabetes, osteoporosis and neurodegenerative diseases (Grafet al, 2005).

Anthocyanins are the water soluble pigments responsible for the brilliant orange red through deep purple colors in flower and fruits (Wong, 1996). They are polar molecules, thus the most common solvents used for its extraction are aqueous mixtures of ethanol, methanol or acetone (Kahkonan et al, 2001), acidified alcoholic solvents (Philip, 1974) and even water only (Esselen and Sammy, 1975). They contribute to the most important attributes of food, like aesthetic value and quality judgment. Their metal chelating capability, together with radical scavenging property, has enabled phenolic compounds to be considered effective antioxidant derived from natural plants ( Lopes et al, 1999), that protect human body from the attack of free radicals, retard the progress of many chronic diseases (Pyror, 1991), and lipid oxidative rancidity in foods. Thermal stability of anthocyanins varies with temperature and $\mathrm{pH}$. It is the most stable and highly colored at low $\mathrm{pH}$ values and gradually loses its color as the $\mathrm{pH}$ increases. However, if the product being colored contains components capable of acting as co pigments, color may be retained and also, the light stabilized it to certain extent (Bobbio et al, 1992). The presence of oxygen and interaction with other components, like sugar and ascorbic acid, also affect on its stability. reported that the degradation of blackberry's anthocyanins increased with increasing heating temperature from 60 to $90^{\circ} \mathrm{C}$ for 
different times.

Water caltrop (Trapa bispinosa) belongs to the family Trapaceae, is an aquatic nut crop grown as submersed plant community mainly in the tropical and sub-tropical region and has special taste and medical function, Due to high activity of enzymes and phenolics content, the color of water caltrop hulls easily changes from the original pink to dark brown color during transportation and processing. Hence, the aim of this study was to extract anthocyanin pigment from water caltrop hull at different extraction conditions.

\section{Materials \& Methods}

Fresh water caltrops were collected from Biratnagar, Morang Nepal. The hulls were separated manually, cleaned in pure water, dried at $55 \pm 5^{\circ} \mathrm{C}$ for $12 \mathrm{~h}$, milled and then sieved into 300, 690 and $1180 \mu \mathrm{m}$ particle size. The fresh and dried hulls were analyzed for anthocynanin and total polyphenol content. The effect of different processing variables $\mathrm{pH}(3,5,7)$, particle size $(300,690$, $1180 \mu \mathrm{m})$, extraction temperature $\left(30,55,80^{\circ} \mathrm{C}\right)$ and time $(10,35,60 \mathrm{~min})$ on the aqueous extraction of anthocyanin were studied. Response surface methodology (RSM) was used for the experimental design (Table 3) using a threelevel; four-factor Central Composite Face centered Design (Mayers et al, 1976). A numerical multi-response optimization was applied to determine the optimum combinations of extraction variables. Similarly the effect of extraction method (acidified ethonal, acidified methonal and $\mathrm{pH}$ differential) from particle size of 300 , $690,1080 \mu \mathrm{m}$ on anthocynanin and total polyphenol extraction, and antioxidant activity in the extracts were studied. The correlation between anthocyanin content and antioxidant activity was also determined.

\section{Determination of chemical parameters:}

Moisture content (hot air over method), crude fat (ether extraction method), protein (micro-Kjeldahl), crude fiber, ash content and the $\mathrm{pH}$ of the extract ( $\mathrm{pH}$ meter) were determined as per Ranganna (2010).

\section{Extraction and determination of anthocyanins:}

The total anthocyanins in aqueous extract was measured as per Shrivastava and Kumar (2002) with some modification. Briefly, to $3 \mathrm{~mL}$ of the extract, $15 \mathrm{~mL}$ of 0.1 $\mathrm{N} \mathrm{HCl}$ was added. Then it was allowed to equilibrate in the dark for $1 \mathrm{~h}$. The absorbance was measured at $510 \mathrm{~nm}$ using a spectrophotometer.

The total anthocyanins in acidified ethanol $(95 \%$ ethanol and $1.5 \mathrm{~N} \mathrm{HCL}$ in ratio $85: 15$ ) extract was measured as per Shrivastava and Kumar (2002). One gram of the dried samples was blended with $5 \mathrm{~mL}$ of acidified ethanol and diluted to $25 \mathrm{ml}$. . The mixture was allowed to stand overnight in a refrigerator at $4^{\circ} \mathrm{C}$, and optical density was measured at $535 \mathrm{~nm}$ using a spectrophotometer.

The anthocyanin content in the extract by acidified methanol ectraction method (methanol: water: $\mathrm{HCl}$, 79:20:1, v/v) was determined as per Mancinelli et al, (1975). Briefly, to $1 \mathrm{~g}$ dried samples, $20 \mathrm{~mL}$ of acidified methanol was added and allowed to stand at refrigeration for $72 \mathrm{~h}$ in the dark. The extracts were then centrifuged for 10 minutes at $5000 \mathrm{rpm}$ and the absorbance was measured at 530 and $657 \mathrm{~nm}$. The absorbance readings at $530 \mathrm{~nm}\left(\mathrm{~A}_{530}\right)$ were corrected for scattering using the absorbance readings at $657 \mathrm{~nm}\left(\mathrm{~A}_{657}\right)$ using formula as following:

$$
\mathrm{A}=\mathrm{A}_{530}-1 / 3 \mathrm{~A}_{657}
$$

Total anthocyanin in the extract by $\mathrm{pH}$ differential method was determined as per Wrolstad and Giusti (2001) with slight modification. One gram of the sample was dissolved in $50 \mathrm{~mL}$ buffers of $\mathrm{pH} 1$ and 4.5 seperately and the absorbances were recorded at 510 and $700 \mathrm{~nm}$ against a blank cell containing deionized water. The absorbance (A) of the samples were calculated as follows:

$$
\mathrm{A}=\left(\mathrm{A}_{510 \mathrm{~mm}}-\mathrm{A}_{700 \mathrm{~nm}}\right)_{\mathrm{pH} 1.0}-\left(\mathrm{A}_{510 \mathrm{~mm}}-\mathrm{A}_{700 \mathrm{~mm}}\right)_{\mathrm{pH} 4.5}
$$

Anthocyanin content $(\mathrm{mg} / 100 \mathrm{gm})=(\mathrm{A} \times \mathrm{MW} \times \mathrm{DF} \times$ $10) /(\varepsilon \times 1)$

Where, MW is molecular weight (449.2) of cyaniding3 glucoside; DF is dilution factor $(60) ; \varepsilon$ is molar absorptivity constant $(29,600)$

Determination of total polyphenols content: Total phenols content was determined by using FolinCiocalteu reagent (Singleton and Rossi, 1965) and expressed as gallic acid equivalent (GAE) / $\mathrm{mg}$ of extract on $\mathrm{db}$, with slight modification Briefly, to $0.5 \mathrm{~mL}$ of an aqueous extract sample, $2.5 \mathrm{~mL}$ of dilute Folin-Ciocalteu reagent (10 fold, $\mathrm{v} / \mathrm{v})$ and $2 \mathrm{~mL}$ of sodium carbonate $(7.5 \%)$ were added The mixture was kept for $5 \mathrm{~min}$ at 50 ${ }^{0} \mathrm{C}$, cooled and the absorbance was measured at $760 \mathrm{~nm}$ using digital specotrophotometer.

Determination of antioxidant activity: Antioxidant activity was determined as DPPH free radical scavenging activity or $\mathrm{IC}_{50}(\mu \mathrm{g} / \mathrm{mL})$ as described by Marinova and Batchvarov (2011). To $1.5 \mathrm{~mL}$ diluted aqueous extract sample, $1.5 \mathrm{ml}$ of $0.06 \mathrm{mM}$ DPPH solution was mixed. It was then stored in dark for 30 minutes and absorbance at $517 \mathrm{~nm}$. The percentage of DPPH scavenging was calculated as follows: 
DPPH radical scavenging activity $(\%)=\left[\left(\mathrm{A}_{\mathrm{c}}-\mathrm{A}_{\mathrm{s}}\right) / \mathrm{A}_{\mathrm{c}}\right] \mathrm{x}$ $100 \%$

Where, $\mathrm{A}_{\mathrm{c}}=$ Absorbance of control at $517 \mathrm{~nm}$ and $\mathrm{A}_{\mathrm{s}}=$ Absorbance of aqueous extract

The concentration of sample necessary to decrease the DPPH concentration by $50 \%$ was obtained by interpolation from linear regression analysis denoted $\mathrm{IC}_{50}$ value $(\mu \mathrm{g} / \mathrm{ml})$.

Statistical analysis: The anthocyanin content as affected by independent variables namely $\mathrm{pH}$ of medium, particle size, temperature and time of extraction was modeled by multiple regression analysis and the statistical significance of the terms was examined by analysis of variance (ANOVA) for each response.: The polyphenols and $\mathrm{IC}_{50}$ value were determined by linear regression using Excel, Microsoft Office, 2010. For significance analysis, the data were separated using Tukey's LSD range at $\mathrm{P}=0.05$. The statistical analysis was performed using SPSS version 20 .

\section{Results and Discussion}

Proximate composition of oven dried hull: The proximate composition of the oven dried hull is given in the Table1. The crude protein, crude lipid and carbohydrate obtained were slightly higher but the crude fiber was slightly less than that obtained by in water caltrops . This may be due to the difference in season and location of the plant grown area. found $79-84 \%$ total fiber in a Norwegian oat hull. The protein content of oat hull was in the range of $2-4.9 \%$ (Welch and Yong, 1980).

Table 1. Proximate composition of oven dried hull

\begin{tabular}{ll}
\hline Composition $\mathbf{~ ( d b ) ~}$ & g/100 g Sample \\
\hline Crude protein & $7.2 \pm 0.9$ \\
Crude lipid & $15.5 \pm 0.5$ \\
Crude fiber & $68.3 \pm 1.2$ \\
Ash & $1.1 \pm 0.3$ \\
Moisture & $15.2 \pm 0.7$ \\
Carbohydrate & 8.2 \\
\hline
\end{tabular}

Values are means \pm standard deviations of three replications

Effect of drying on anthocyanin: The total anthocyanin content of fresh and dried water caltrop hull was 68.68 and $44.38 \mathrm{mg} / 100 \mathrm{~g}$ d.b. (i.e after drying anthocyanin content was decreased by $35.3 \%$ ). This might be due to the degradation of anthocyanin with increasing drying temperature and time (Wang and $\mathrm{Xu}, 2007$ ). The difference in anthocyanin content of fresh and oven dried grape skin; and fresh and oven dried mulberry was reported to be $34.5 \%$ and $41 \%$ respectively (De Torres et al, 2010). Phenolic compounds are often found in the external areas of the vacuoles. Thus, if the cellular structure deteriorates during the drying process, the compounds stored outside of the organelles are more sensitive to degradation, which should have been more

Table 2. Effect of Extraction method and particle size on Anthocyanin extraction

\begin{tabular}{llc}
\hline Method & Particle size $(\boldsymbol{\mu m})$ & Total anthocyanin $(\mathbf{m g} / \mathbf{1 0 0} \mathbf{g ~ d . b})$. \\
\hline Using Acidified Ethanol & 300 & $38.65 \pm 0.42^{\mathrm{b}}$ \\
& 690 & $37.99 \pm 0.31^{\mathrm{a}}$ \\
& 1080 & $36.85 \pm 0.57^{\mathrm{a}}$ \\
Using Acidified Methanol & 300 & $50.27 \pm 1.25^{\mathrm{e}}$ \\
& 690 & $47.38 \pm 0.68^{\mathrm{d}}$ \\
pH differential & 1080 & $43.32 \pm 0.79^{\mathrm{c}}$ \\
& 300 & $39.76 \pm 0.57^{\mathrm{b}}$ \\
& 690 & $39.47 \pm 0.77^{\mathrm{b}}$ \\
\hline
\end{tabular}

Values are means \pm standard deviations of three replications

marked in the case of anthocyanin (Chism and Haard, 1996).

Effect of extraction method and particle size: The effect of extraction method and particle size on the anthocyanin extraction were significant but there was no significant difference in the anthocyanin content for 690 and $1080 \mu \mathrm{m}$ by acidified ethanol extraction and for 300 
and $690 \mu \mathrm{m}$ by $\mathrm{pH}$ differential method. Similarly there was no significant difference in anthocyanin extraction from $1080 \mu \mathrm{m}$ by acidified ethanol and $\mathrm{pH}$ differential

Effects of variables on aqueous extraction of anthocyanin: The aqueous extraction of anthocyanin at different conditions with respect to total anthocyanin in method. There was an interaction between particle size and extraction methods on anthocyanin extraction $(p>0.05)$ as shown by Table.2.

oven dried water caltrop varied from $27.5 \%$ to $67.8 \%$ (Table 3; Fig. $1 \&$ 2) The results were in agreement with the research work reported by Fan et al., (2008).

Table 3: Effect of variables on aqueous extraction of anthocyanin

\begin{tabular}{lllll}
\hline \multicolumn{2}{l}{ Experimental design for aqueous extraction } & & \% Anthocyanin \\
\hline Initial $\mathrm{pH}$ & Size & Tem $\left({ }^{\circ} \mathrm{C}\right)$ & Time $($ Min $)$ & 29.7 \\
\hline 3 & 300 & 30 & 10 & 33.8 \\
7 & 300 & 30 & 10 & 27.5 \\
3 & 1080 & 30 & 10 & 30.3 \\
7 & 1080 & 30 & 10 & 61.9 \\
3 & 300 & 80 & 10 & 66.7 \\
7 & 300 & 80 & 10 & 42.4 \\
3 & 1080 & 80 & 10 & 51.4 \\
7 & 1080 & 80 & 10 & 31.8 \\
3 & 300 & 30 & 60 & 36.1 \\
7 & 300 & 30 & 60 & 29.2 \\
3 & 1080 & 30 & 60 & 30.9 \\
7 & 1080 & 30 & 60 & 60.9 \\
3 & 300 & 80 & 60 & 67.8 \\
7 & 300 & 80 & 60 & 53.1 \\
3 & 1080 & 80 & 60 & 54.4 \\
7 & 1080 & 80 & 60 & 42.2 \\
3 & 690 & 55 & 35 & 50.5 \\
7 & 690 & 55 & 35 & 58.8 \\
5 & 300 & 55 & 35 & 40.4 \\
5 & 1080 & 55 & 35 & 32.5 \\
5 & 690 & 30 & 35 & 55.1 \\
5 & 690 & 80 & 35 & 44.5 \\
5 & 690 & 55 & 10 & 61.7 \\
5 & 690 & 55 & 60 & 53.2 \\
5 & 690 & 55 & 35 & 58.6 \\
5 & 690 & 55 & 35 & 52.8 \\
5 & 690 & 55 & 35 & 59.3 \\
5 & 690 & 55 & 35 & \\
5 & 690 & 55 & 35 & 35 \\
5 & 690 & 55 & & \\
\hline
\end{tabular}




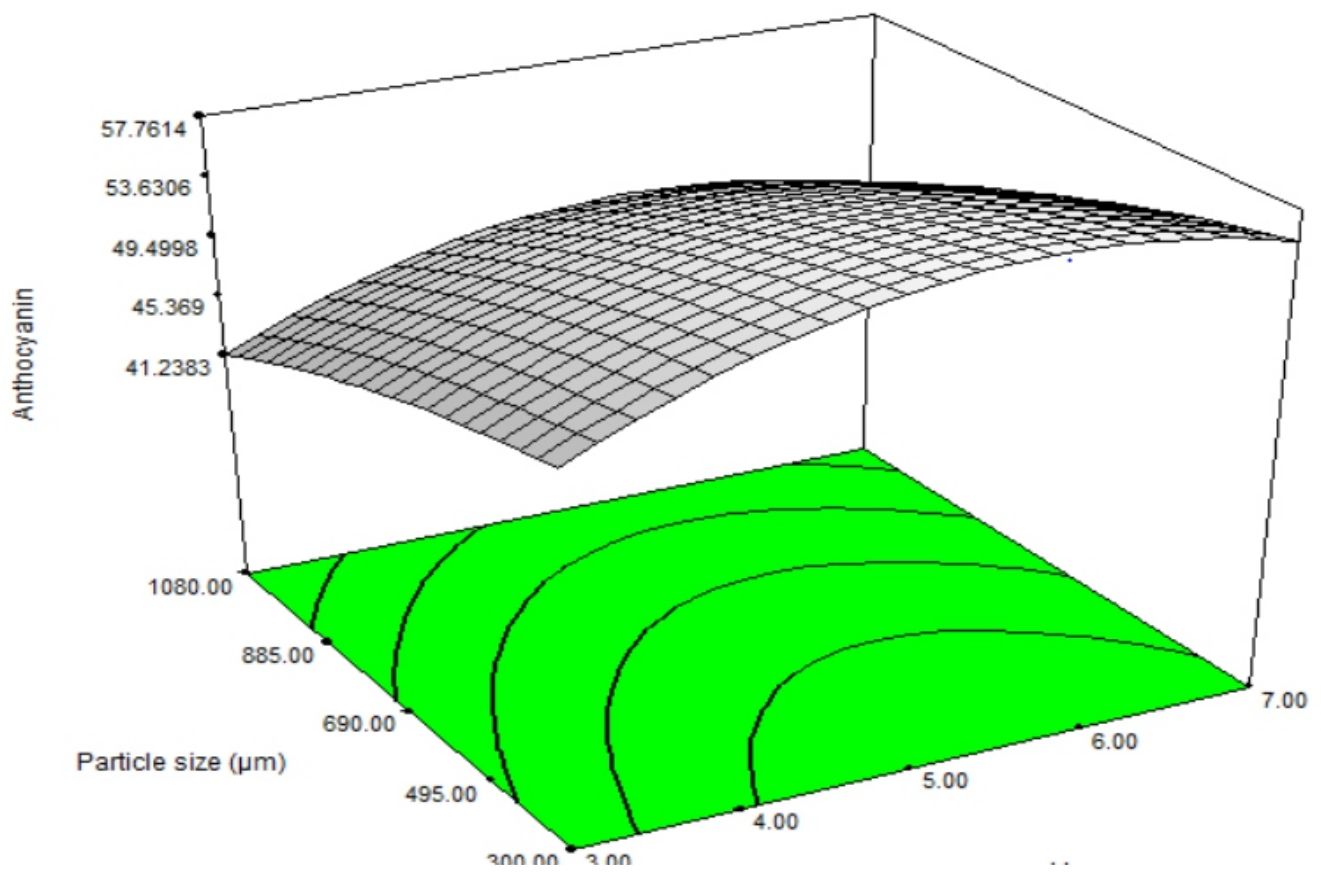

Fig 1. Response surface plot for $\%$ anthocyanin extraction as a function of particle size and $\mathrm{pH}$

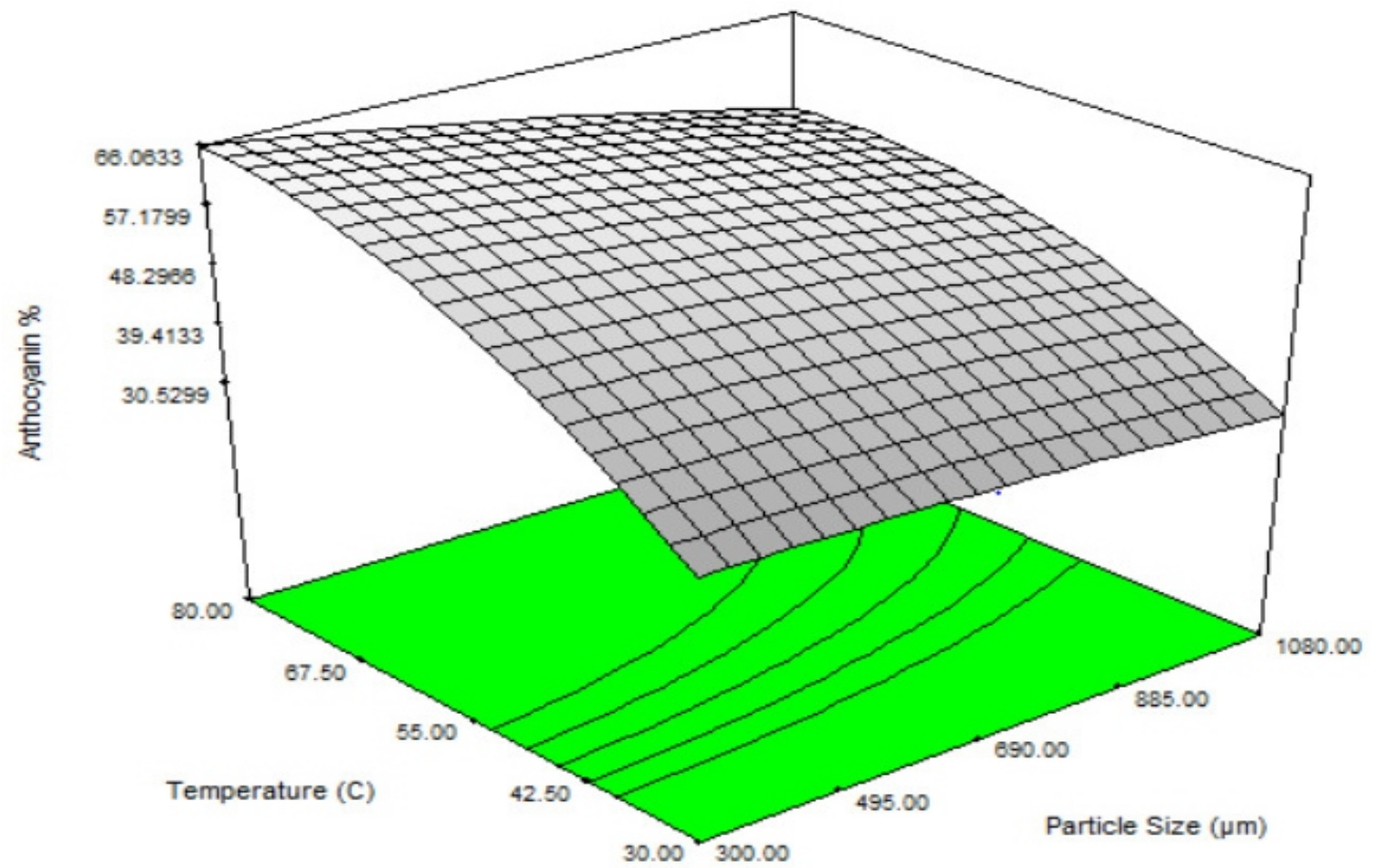

Fig 2. Response surface plot for $\%$ anthocyanin extraction as a function of temperature and particle size

The Figure 3 shows that decreasing particle size increase the anthocynin extraction. found higher yields in total phenolics and anthocyanins in the extract with decrease in pomace size of black currant juice residues. Increasing extraction temperation increased the anthocyanin extraction (Fig. 4) Increase in temperature favors the extraction by increasing the solubility of anthocyanins and increasing the diffusion coefficient (). The anthocyanins contain from purple sweet potato was significantly affected by temperatures on acid-ethanol solvent extraction (Fan et al, 2008). 


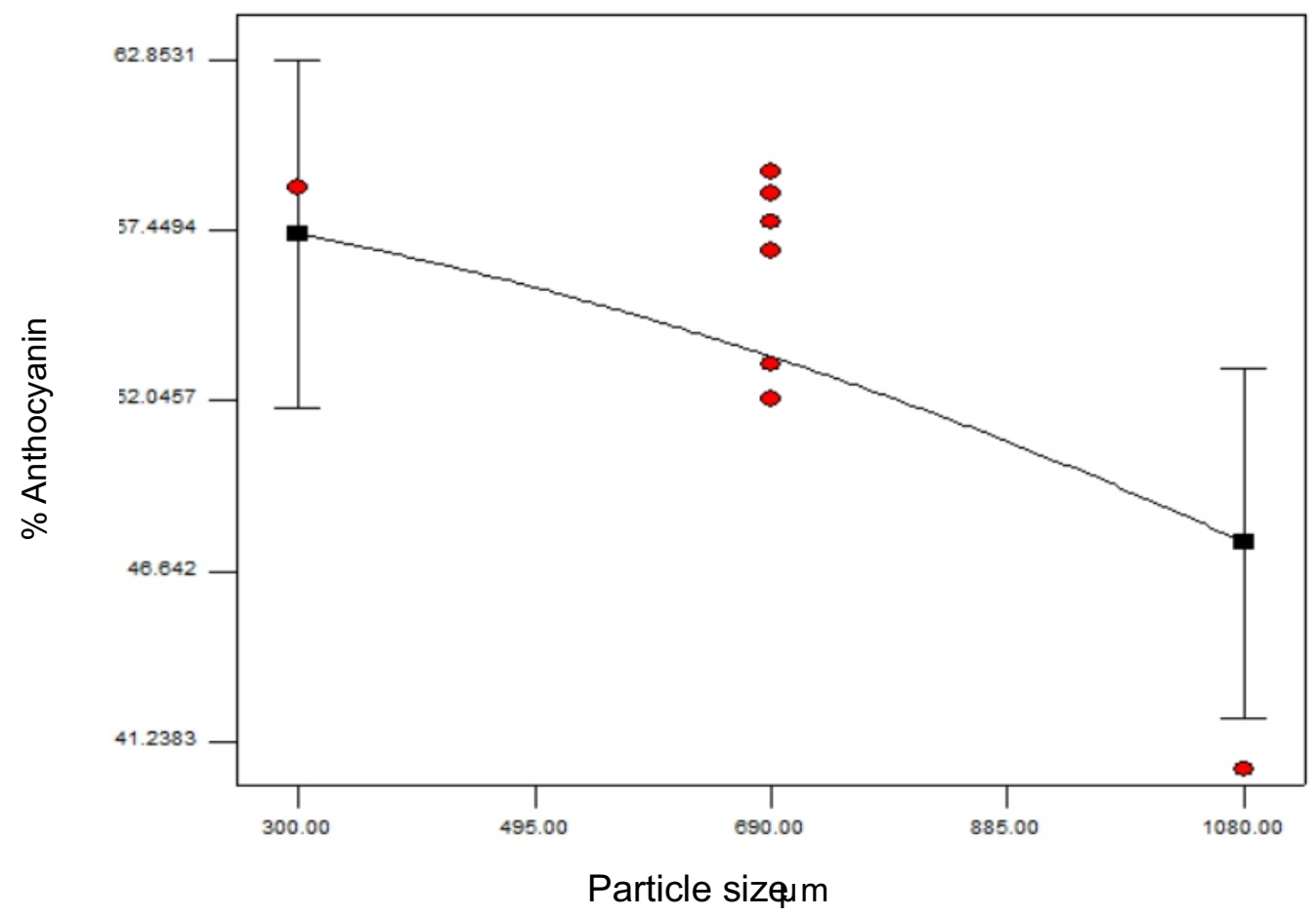

Fig 3. One factor plot for $\%$ extraction of anthocyanin as function of Particle size $(\mu \mathrm{m})$.

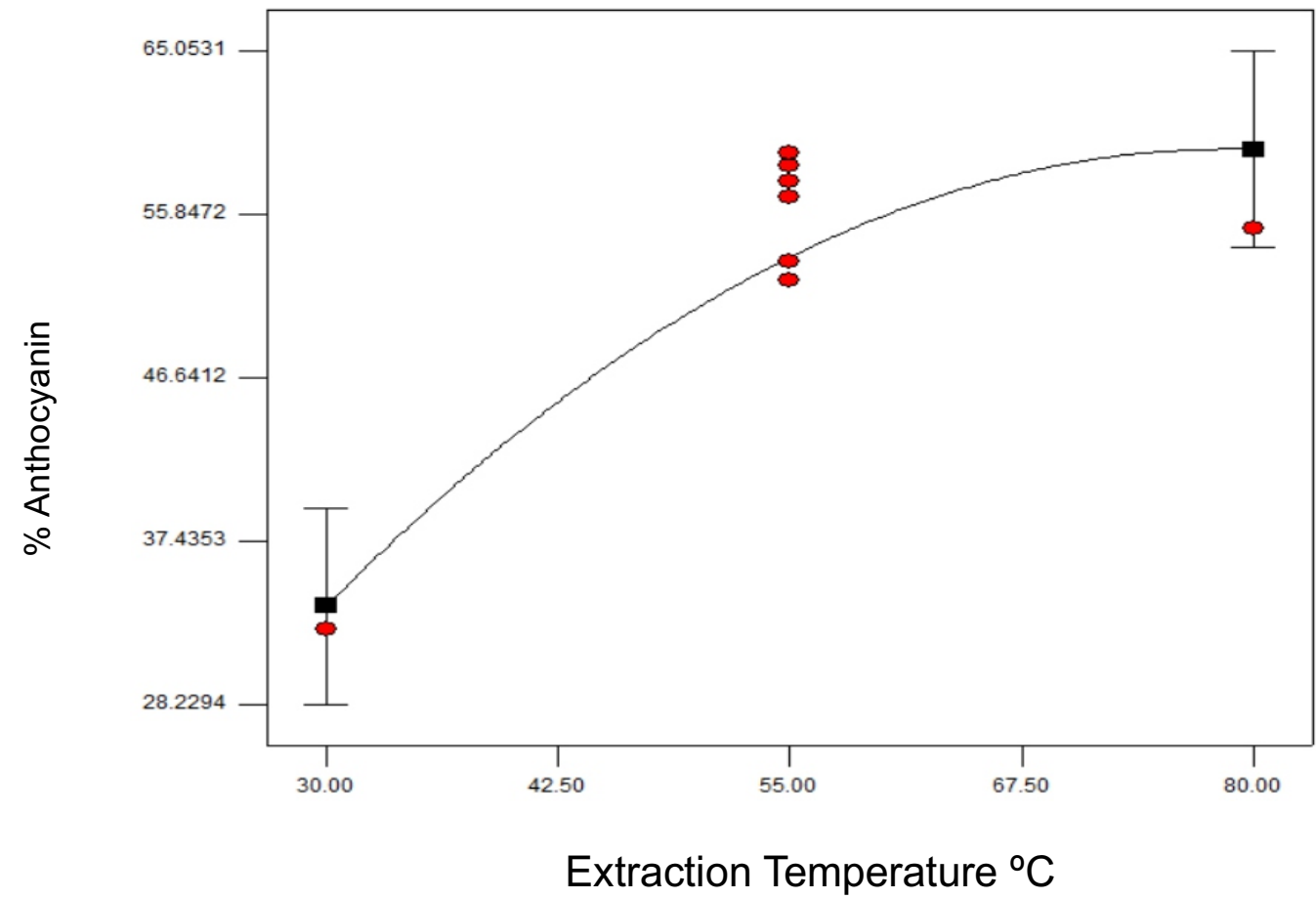

Fig 4. Response surface plot for $\%$ anthocyanin extraction as a function of temperature and particle size

Effect of Particle size on Total Polyphenols: The total polyphenol content in the extracts were 55.02, 56.31 and $60.31 \mathrm{mg} \mathrm{GAE} / \mathrm{g} \mathrm{dm}$ for particle sizes of 1080,690 and $300 \mu \mathrm{m}$ respectively. The polyphenol contents of $300 \mu \mathrm{m}$ was significantly higher than those of 690 and $1080 \mu \mathrm{m}$, while there was no significant difference in the polyphenol contents between 690 and $1080 \mu \mathrm{m}$ sizes (Fig $5, p>0.05)$. The total phenolics in methanolic extracts of water calrop hull ranged from 5.21 to $8.59 \mathrm{~g} \mathrm{GAE} / 100 \mathrm{~g}$, . (Jhih-Ying et al, 2007). 


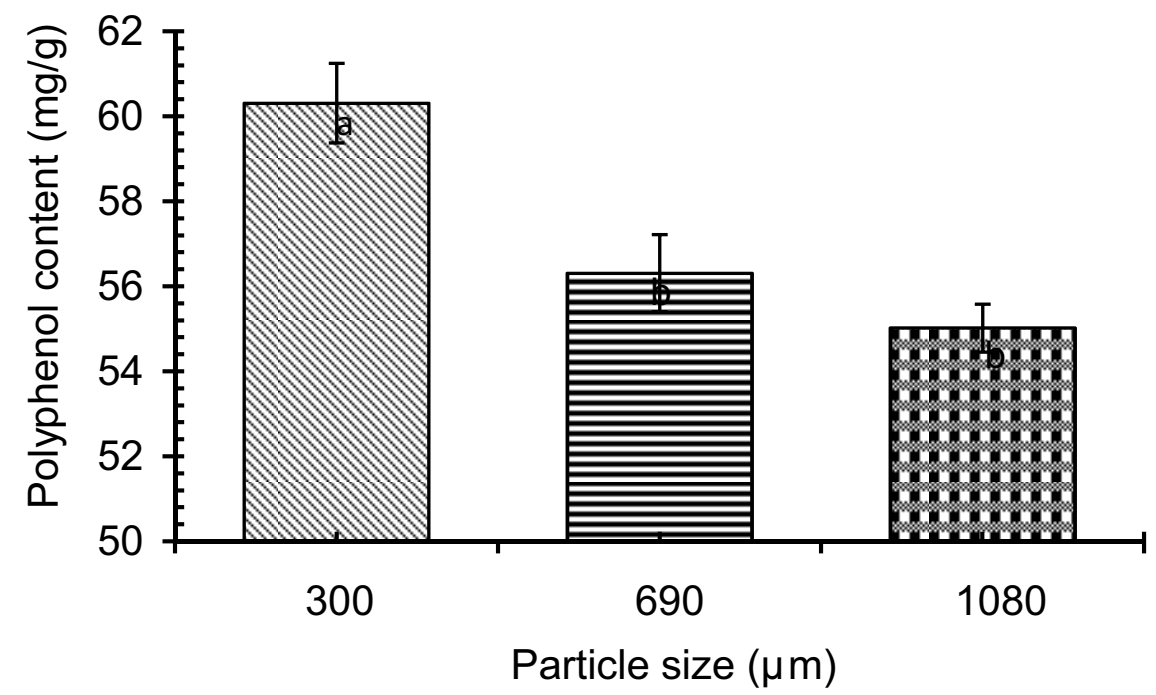

Fig. 5 Total polyphenol content of aqueous extract for different particle size

Effect of particle size on antioxidant activity: Particle $300 \mu \mathrm{m}$ showed lowest IC50 value $(173.36 \mu \mathrm{g} / \mathrm{mL})$, followed by $690 \mu \mathrm{m}(187.73 \mu \mathrm{g} / \mathrm{mL})$ whereas $1080 \mu \mathrm{m}$ showed the highest IC50 value $(193.69 \mu \mathrm{g} / \mathrm{mL})$ which were significantly different from each other $(p<0.05)$. The results were similar to those obtained in research by, which was reported to be $2 \mathrm{mg} / \mathrm{mL}$ concentrations for scavenging activity of $79.3 \%$ for hot air dried water caltrop hulls. Similarly, determined the scavenging ability of DPPH free-radical and the value was $78.3 \%$ at the dose of the $250 \mu \mathrm{g} / \mathrm{mL}$ methanolic extracts for dried water caltrop hulls.

\section{Conclusion}

Water caltrop hull contains substantial amount of anthocyanin. Drying temperature affected the anthocyanin content in the water caltrop hull. Percentage extraction of anthocyanin was affected by $\mathrm{pH}$ of the extraction medium, particle size of water caltrop hull, extraction temperature and time. Increasing particle size and temperature increased anthocynanin extraction.

\section{References}

Bobbio FO, Bobbio PA and Stringheta PC. Stability of copigmented anthocyanins from Panicum melinis toward light and oxygen at different $\mathrm{pH}$. Bull. Liaison-Groupe Polyphenols 1992, 16(1), 241-4.

Bravo L. Polyphenols: Chemistry, dietary sources, metabolism, and nutritional significance. Nutr Rev 1998, 56, 317-33.

Cacace JE and Mazza G. Optimization of extraction of anthocyanins from black currants with aquous ethanol. J. Food Science 2003b, 68(1), 240-8.

Chiang PY and Ciou JY. Effect of Pulverization on antioxidant activity of Water caltrop (Trapa taiwanensis Nakai) Pericarp. LWT- Food Science and Technology. 2010 (43), 361-5.

Chism GW and Haard NF. Food Chemistry (O.R. Fennema ed.). Dekker New York. 1996.

De Torres C, Diaz-Marotoa MC, Hermosín-Gutiérrezc I and Pérez-Coelloa MS. Effect of freeze-drying and oven-drying on volatiles and phenolics composition of grape skin. Analytica Chimica Acta.660, 2010, $177-82$.
Esselen WB and Sammy GM. (1975). Food Product Development. 9, 37. [Cited in G. Gartaula. (2009). Extraction of Anthocyanins from Roselle (Hibiscus sabdariffa var. sabdariffa) using aqueous medium. M. Tech. (Food) Dissertation. Tribhuvan University, Nepal].

Fan G, Han Y Gu , and Chen D. Optimizing conditions for anthocyanins extraction from purple sweet potato using response surface methodology (RSM). Lebensm. Wiss. u. Technol. 2008, 41, 155-60.

Frolich W and Nyman M. Minerals, phytate and dietary fibre in different fractions of oat-grain. J of Cereal Sci , 1998, 7, 73-82

Graf B, Milbury $\mathrm{P}$ and Blumberg J. Flavonols, Flavones, Flavanones, and Human Health, Epidemiological Evidence. J. of med. food. 2005, 8, 281-90.

Jhih-Ying C, Chiun-C RW, Jacob C and Po-Yuan C. Total Phenolics Content and Antioxidant Activity of Extracts from Dried Water Caltrop (Trapa Taiwanensis Nakai) Hulls, J of Food and Drug Ana. 
2007, 16(2), 41-47.

.Kahkonan MP, Hopia, AI. and Hoinonen, M. Berry phenolics and their antioxidant activity. J. Agric. Food. Chem. 2001, 49(8), 859-71.

Lopes GKB, Schulman HM and Hermes-Lima M. Polyphenol tannic acid inhibits hydroxyl radical formation from fenton reaction by complexing ferrous ions. Biochim Biophys. Acta. 1999, 14, 14252.

Maillard MN, Soum MH, Boivia P and Berset C.). Antioxidant activity of barley and malt: relationship with phenolic content. LWT Food Sci Technol. 1996, 3,238-44.

Mancinelli AL, Yang CPH, Lindquist P, Anderson OR and Rabino I. Photocontrol of anthocyanin synthesis. III. The action of streptomycin on the sysnthesis of chlorophyll and anthocyanin. Plant Physiol. 1975, (55), 261-7.

Marinova $G$ and Batchvarov V. Evaluation of the methods for the determination of the free radical scavanging activity by DPPH. Bulg. J. of Agric. Sci. 2011, 17, 11-24.

Pandey KB and Rizvi SI. Plant polyphenols as dietary antioxidants in human health and disease. Oxid. med. cell Longev. 2009, 2(5), 270-8.

Philip T. Extraction of Anthocyanins from Roselle (Hibiscus sabdariffa var. sabdariffa) using aqueous medium. M. tech. (Food) Dissertation. 2009, Tribhuvan University, Nepal].
Pyror WA. The antioxidant nutrients and disease prevention- what do we know and what do we need to find out? Am. J. Clin. Nutr 1991, 53, 391-3.

Ranganna S. Hand book of Analysis and Quality control for fruit and vegetable products. 2010, (2nd ed), Tata McGraw-Hill Publishing company Ltd, New Delhi.

Shrivastava RP and Kumar S. Fruit and Vegetable preservation- principles and practices 2002, (3rd ed). International book distributing co Lucknow, India.

Singleton VL and Rossi JA. Colorimetry of Total Phenolics with Phosphomolybdic-Phosphotungstic Acid Reagents, American J of Enology and Viticulture. 1965, 16, 144-58.

Wang, WD and Xu SY. Degradation Kinetics of anthocyanins in black berry juice and concentrate. J. Food Eng. 2007, 82, 271-5.

Welch, RW and Yong YY. The effects of variety and nitrogen fertiliser on protein production in oats. J of the Sci of Food and Agri 1980, 31, 541-8.

Wong, DWS. Mechanism and Theory in Food Chemistry (1st ed.). CBS Publishers and Distributors, India, 1996.

Wrolstad, RE and Giusti MM. Characterization and measurement of anthocyanins by UV-Vis spectroscopy. In: "Current Protocols in Food Anal. Chemistry". 2001 (R.E.Wrolstad, Ed.). NewYork, Wiley Inc. 